\title{
Mortality risks and child labor
}

\author{
Fernanda Estevan Jean-Marie Baland
}

\begin{abstract}
This paper aims to contribute to the literature on child labor by investigating the role of lifetime uncertainty on the supply of child labor. More specifically, we examine the impact that the child's lifetime uncertainty may have on the parents' decision to send their child to school or to work, in the absence of insurance mechanisms. We show that the level of child labor may be inefficiently high if parents are not altruistic towards their children and expect to receive filial transfers. However, if the parents are altruistic and expect to leave positive net bequests to their children, the level of child labor they choose is inefficiently low. Finally, we investigate a potential efficiency-restoring policy intervention, namely cash transfers conditional on child's schooling, and we show that it may restore efficiency in parents' decision concerning child labor.
\end{abstract}

Provisional version. Please do not circulate, do not quote. 


\section{Introduction}

Child labor is a pervasive but declining phenomenon. According to the International Labor Organization there were some 211 million children aged 5 to 14 at work in economic activity in the world in 2000. This accounts for a little less than one-fifth of all children in this age group. These figures are lower than the 1995 estimates when there were 250 million $^{1}$ working children in the world.

Child labor is highly concentrated in developing countries. Only 4.9 million of working children live in developed and transition economies. The Asian-Pacific region accounts for $60 \%$ of world working children, and in Sub-Saharan Africa we find the highest proportion of working children, $29 \%$.

The apparent decrease in the number of working children seems to be accompanied by an increase in the concern for child labor. The rapidly growing theoretical and empirical literature in the field illustrates this fact. A great part of the theoretical literature investigates the determinants of child labor as a precondition for the prescription of appropriate policies. We adopt Couralet (2002)'s distinction between macroeconomic and microeconomic models in this field, and briefly give an idea of the main differences between them.

Part of the literature on child labor adopts a macroeconomic-based analysis to try to explain the occurrence of working children. In a seminal paper, Basu and Van (1998) show that, if adult and child labor are substitutes and parents send their pupils to work only if non-child labor sources are low, there is scope for multiple equilibria. In such a setting, there is a role for benign policy interventions that move the economy from the bad equilibrium, with both children and adults working and low wages, to a good equilibrium, in which children do not work and wages are high.

Simultaneously, a more microeconomic-oriented approach tries to answer the same question but considers the household as the unit of analysis. These models try to understand how child labor can arise as the outcome of a rational decision from parents who take into account the trade-off between child labor and schooling. In this setting, there are two possible explanations for the incidence of child labor. The first possibility is that private returns from education are not high enough to encourage education investment in countries with a high incidence of child labor. This view is apparently contradicted by several empirical studies, such as Psacharopoulos (1997) which shows that returns from education are relatively high in developing countries. ${ }^{2}$

\footnotetext{
${ }^{1}$ The 1995 estimates did not include children at work in developed and transition economies, due to lack of data. For this reason, this figure should be compared with 206 million in 2000, if one subtracts roughly 5 million working children in developed and transition economies.

${ }^{2}$ However, Couralet (2002) argues that many estimations of the rate of return to education in developing countries are over-valuated with respect to the return anticipated by parents. He points
} 
The second possibility is that several constraints force parents to take inefficient decisions with respect to child labor. This idea is the heart of Baland and Robinson's (2000) model. Since their model is the basis of the present study, we present its main assumptions and results in more detail.

Baland and Robinson (2000) assume that there is a trade-off between child labor and the accumulation of human capital. In a model in which parents are fully altruistic with respect to their children, they show that an inefficiently high level of child labor may arise when parents leave their children no bequests or when capital markets are imperfect. The reason is that in these two situations parents cannot lower bequests or borrow money in order to finance education investment and raise their child's future earnings. ${ }^{3}$

A corollary to Baland and Robinson's (2000) two-sided altruism model is that, with perfect capital markets, parents should always choose the privately efficient level of child labor. They do so by equalizing the marginal return to education in terms of income with the opportunity cost in terms of lower child labor, borrowing money against their child's future wages if necessary.

Obviously the attainment of an efficient level of child labor strongly relies on the assumption that parents perfectly anticipate the marginal return to their child's education. We briefly present some arguments borrowed from the economics of education literature as to why this is probably not the case.

Becker (1964) introduced the idea that human capital investment was subject to risk. Subsequent studies consider the trade-off between human capital and physical capital investment assuming that returns to education are difficult to anticipate since they are affected by risk.

In Levhari and Weiss (1974) two kinds of uncertainty are taken into account. First, parents observe neither their children's abilities nor the quality of schooling. Consequently, they do not know whether education investment will result in better work opportunities and higher wages in the future. Second, future labor market

out some factors to justify this assessment. First, the great heterogeneity of education quality in developing countries induces a selection bias: the better the quality of education, the longer the duration of the studies. As a consequence, the ex post return to education (the estimated one) is over-valuated with respect to the one parents have considered when their decision of whether to send their pupils to school or not was taken. Also, several computations of returns to education do not take into account the socioeconomic origin of the individual, which also contributes to an over-valuation of these returns.

${ }^{3}$ This finding seems to be confirmed in the light of empirical studies. The impact of liquidity constraints on child labor was investigated in Edmonds (2004) using South African data. He considers the response of child labor supply and schooling attendance to anticipated social pension income in that country. He shows that once households become eligible for the pension income, child labor declines and schooling increases, suggesting the presence of liquidity constraints. 
conditions are subject to more or less unpredictable events. To our knowledge, no model on child labor has been developed taking these kinds of risk into consideration. Indeed, it is unclear whether such risks are more prevalent in developing economies than in more developed ones. It therefore appears as an unlikely key mechanism for explaining the prevalence of child labor in the former.

However, there is another kind of uncertainty related to human capital investment that definitely affects more severely developing countries, and therefore may constitute an important mechanism in underlying child labor: the uncertainty related to a child's lifetime which affects the duration of future earnings and, consequently, returns to education. ${ }^{4}$

In this paper we modify Baland and Robinson (2000)'s two-sided altruism model to account for children's lifetime uncertainty. We show that even if capital markets are perfect and there are positive intergenerational transfers, the level of child labor the parents choose can be inefficient due to lifetime uncertainty.

This paper is organized as follows. In Section 2, we present some evidence on mortality rates to illustrate that lifetime uncertainty is a relevant issue in developing countries, and a brief survey of the relevant literature on lifetime uncertainty and child labor. In Section 3, we introduce the basic model in which we consider that parents do not have access to perfect insurance. In Section 4, we analyze how the availability of perfect insurance modifies the equilibrium level of child labor, and in Section 5 we present our main results. In Section 6 we analyze the effectiveness of some policy interventions to restore efficiency, and in Section 7, we conclude.

\section{Lifetime Uncertainty and Child Labor}

Table 1 presents some evidence on life expectancy and mortality rates for selected countries.

These figures illustrate the huge differences in life expectancy between developing and developed countries, but also the large discrepancies among developing countries. As an example, life expectancy is 78.3 years in Germany, and 63.9 in India, whereas in Zambia it attains only 32.4 years. As a general pattern, in Asian and Latin American countries a person lives 10 to 15 years less than in developed countries but up to 30 years more than in some African countries.

Infant and under-five mortality rates certainly explain part of these differences in life expectancy. However, they are probably not very relevant to explain investment

\footnotetext{
${ }^{4}$ Razin (1976) builds a model in which he shows that there is a certain advantage in investing in physical capital as compared to investing in human capital. This difference is due to the noninheritability of human capital, and explains the fact that the marginal rate of return to investment in human capital exceeds the marginal rate of return to physical capital.
} 
Table 1: Demographic figures

\begin{tabular}{|c|c|c|}
\hline Country & $\begin{array}{c}\text { Life } \\
\text { expectancy } \\
\text { at birth } \\
\text { years } \\
2000-05\end{array}$ & $\begin{array}{c}\text { Mortality rate } \\
\text { between } \\
\text { ages } 5 \text { and } 40^{a} \\
\text { (per } 1,000 \text { births) } \\
2002\end{array}$ \\
\hline Japan & 81.6 & 14 \\
\hline Germany & 78.3 & 16 \\
\hline China & 71.0 & 32 \\
\hline United States & 77.1 & 34 \\
\hline Mexico & 73.4 & 47 \\
\hline India & 63.9 & 60 \\
\hline Indonesia & 66.8 & 63 \\
\hline Guatemala & 65.8 & 92 \\
\hline Mali & 48.6 & 131 \\
\hline Senegal & 52.9 & 139 \\
\hline Ghana & 57.9 & 158 \\
\hline Gambia & 54.1 & 170 \\
\hline Sudan & 55.6 & 182 \\
\hline Burkina Faso & 45.7 & 227 \\
\hline Chad & 44.7 & 229 \\
\hline Ethiopia & 45.5 & 262 \\
\hline Uganda & 46.2 & 270 \\
\hline Cameroon & 46.2 & 276 \\
\hline Burundi & 40.9 & 315 \\
\hline Cote d'Ivoire & 41.0 & 341 \\
\hline Mozambique & 38.1 & 363 \\
\hline Kenya & 44.6 & 373 \\
\hline South Africa & 47.7 & 384 \\
\hline Malawi & 37.5 & 413 \\
\hline Namibia & 44.3 & 456 \\
\hline Zambia & 32.4 & 509 \\
\hline Swaziland & 34.4 & 556 \\
\hline Zimbabwe & 33.1 & 625 \\
\hline
\end{tabular}

Source: Column 1 and 2: Human Development Report 2004, United Nations.

${ }^{a}$ Data refer to the probability at birth of not surviving to age 40 minus under-five mortality rates.

in education since schooling typically takes place after the age of 7 .

More interesting for our purposes are data on mortality rates between ages 5 and 40. In African countries the probability of dying between ages 5 and 40 goes from $15 \%$ to $62.5 \%$ while it reaches less than $10 \%$ in other developing countries, and less than $5 \%$ in developed countries.

This regional pattern allows us to investigate more age range specific data. We concentrate on the age range 15-44 in which compulsory schooling has taken place and individuals are thought to be in their productive years. Figure 1 shows that in such age range, the pattern we have observed in Table 1 is still maintained. Some African countries are still in the top of the list with a probability of dying between 


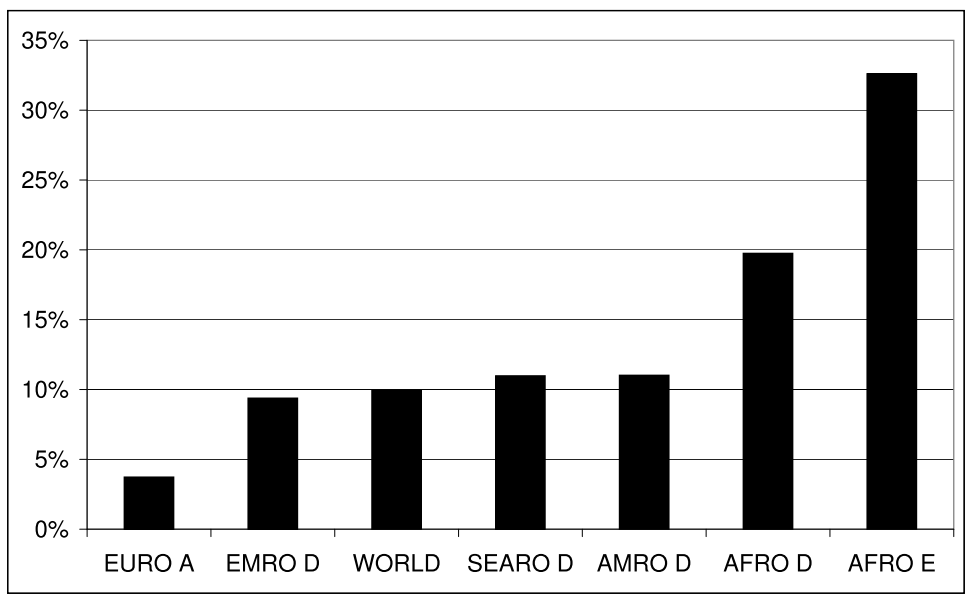

Figure 1: Probability of death between ages 15 and 44 by region

Source: The world health report 2004 - changing history, WHO, UN.

ages 15 and 44 that reaches $32 \%$.

We thus have reasons to believe that uncertainty related to lifetime is a relevant issue, especially in some African countries, in which, as we have already pointed out, the prevalence of child labor is higher.

In this paper we investigate the mechanism underlying the impact of lifetime uncertainty on child labor trying to establish a causal relationship between the prevalence of high adult mortality rates and child labor. Indeed, Figure 2 representing data for 126 developing countries seems not to contradict the existence of a relationship between these two variables.

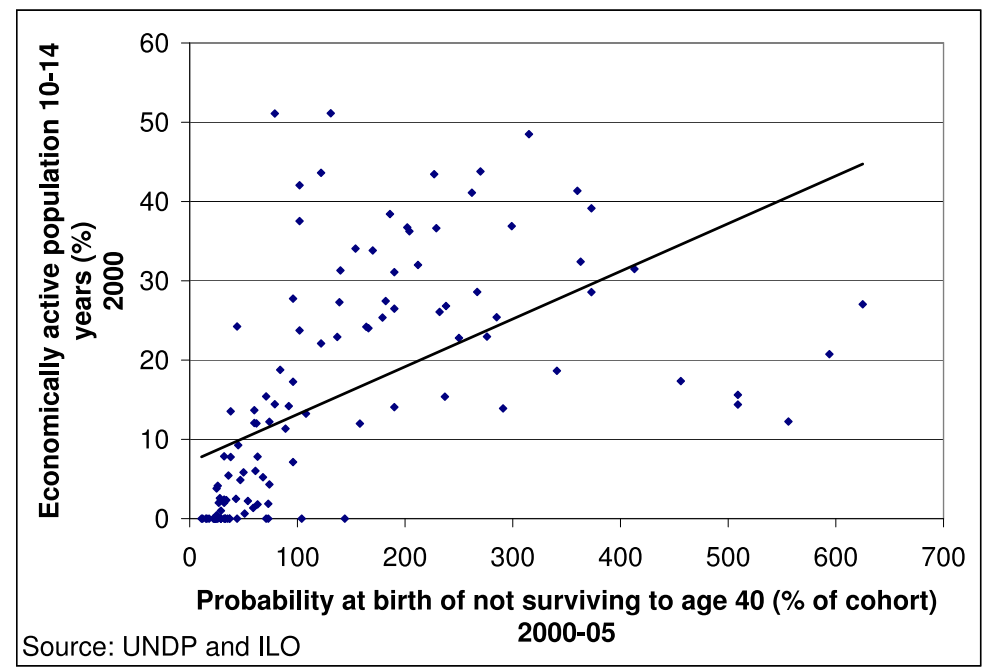

Figure 2: Mortality rates vs. Child labor

The closest paper in the literature is that of Eswaran (2000). In this paper, he builds an old-age security model for fertility in which parents decide on how many 
children to have and whether to send them to school or to work, taking into account that not all of them will live to be adults. However, in his paper, low expected rates of return from education are not the only cause of high levels of child labor in countries with high mortality rates. The association of high mortality rates with lack of access to capital markets, a common feature in developing countries, constrains parents to have several children in order to ensure that some will survive and provide them with old-age support. In such a setting, parents tend to trade off education in favor of child labor for at least two reasons. First, there is a risk component since premature death may prevent parents to receive back part of education investment in the form of old-age support. Second, child labor avoids the need to curtail current consumption in order to increase family size.

Our model differs with respect to Eswaran (2000) in many aspects. First, we allow not only for filial altruism that can be understood as old-age support, but also for parental altruism. We will see that the impact of lifetime uncertainty on child labor depends crucially on the resulting net transfers between parents and children. Second, we treat fertility exogenously ${ }^{5}$, and concentrate on parents' choice between child labor and education. Third, we consider the existence of perfect capital markets and focus instead on the imperfections of insurance markets (against child mortality). As we shall argue, the latter is much more pervasive and has farreaching consequences, even if capital markets are perfect.

More recently, Strulik (2004) builds a growth model combining fertility, child mortality, child labor and education. He shows that if child mortality is high, the solution of the parental decision problem leads to economic stagnation. His results are based on striking different assumptions with respect to our model. We briefly present some of them. First he postulates that parents derive utility directly from child quality expenditure, and so there are no explicit human capital considerations in the parents' decision concerning education. Second there is no role for intergenerational transfers, that, as we will show, are central to the analysis of our results.

\section{First Model: Absence of Perfect Insurance}

We follow Baland and Robinson's (2000) model with two-sided altruism. We consider two periods, $\mathrm{t}=1,2$, and assume that agents do not discount the future.

In each period parents supply labor inelastically up to $A L_{p}$, where $A$ represents

\footnotetext{
${ }^{5}$ We have done the exercise to endogeneize fertility but we omit the results because they simply highlight the well-known quality-quantity trade-off. A decrease in mortality rates has a positive impact on fertility since it increases parent's utility by allowing children to perform transfers to their benefit, and also by parental altruism. However, child labor decreases as a result of the decrease in mortality rates, and so parents' first period utility is negatively affected.
} 
parents' efficiency units of labor in each period, and $L_{p}$ is the number of parents alive in the first period. In the first period, parents decide the fraction of time their child will spend at work, $l_{c} \in[0,1]$, so that the supply of child labor equals $n L_{p} l_{c}$, where $n$ is the number of children that each set of identical parents decide to have. For simplicity, we consider the existence of a representative firm who uses labor to produce the numeraire good, and we normalize all wage rates and $n$ to 1 .

Our model departs from Baland and Robinson's (2000) model with respect to children's lifetime. As in their model, we assume that parents live for both periods. ${ }^{6}$ However, parents are not sure that their child will survive for both periods. More specifically, we let $p$ represent the exogenous probability that a child lives for two periods and $(1-p)$ the exogenous probability that the child dies after the first period $^{7}$. In this Section we assume that the parents do not have access to insurance contracts that would allow them to insure against the risk of the child's death.

If it is alive in the second period, the child, now an adult, supplies labor in the amount of $n L_{p} h\left(1-l_{c}\right)$, where $h\left(1-l_{c}\right)$ represents additional units of human capital possessed by an adult who worked for a fraction $l_{c}$ of his time endowment as a child. We assume that an increase in hours of schooling increases units of human capital, but at a decreasing rate, that is, $h^{\prime}\left(1-l_{c}\right)>0$, and $h^{\prime \prime}\left(1-l_{c}\right)<0$. We assume that $h(0)=1$, and we impose Inada conditions on $h\left(1-l_{c}\right)$, that is, $h^{\prime}(0)=\infty$ and $h^{\prime}(\infty)=0$, to guarantee that the optimal value of $l_{c}$ is interior.

We assume that in the first period parents control all income including child labor income. Therefore the parents face the following budget constraint in the first period

$$
c_{p}^{1}=A+l_{c}-s
$$

where $c_{p}^{1}$ denotes household consumption of the numeraire (whose price we normalize to unit) in the first period, and $s$ represents savings. We assume the existence of perfect capital markets, and parents can either save or borrow. We let $\tilde{c}_{p}^{2}$ and $\bar{c}_{p}^{2}$ denote the parental consumption in the second period if their child is alive and not alive, respectively. For the second period, if their child is alive, the parents' budget constraint is

$$
\tilde{c}_{p}^{2}=A-b+s+\tau
$$

\footnotetext{
${ }^{6}$ One can show that parental mortality alone does not lead to an inefficient level of child labor. When one considers both child and adult mortality, the computations are more complicated and we were not able to derive clear-cut conclusions.

${ }^{7}$ Empirical evidence seems to give support to this assumption of exogenous probability. According to the World health report 2004, in the age range of 15-29 years, $42.5 \%$ of deaths in AFRO E can be attributed to AIDS epidemics, while $18 \%$ are caused by war and violence.
} 
where $b \geq 0$ represents bequests and $\tau \geq 0$ represents a transfer from the child to the parent. If the child does not survive the second period, the parents' budget constraint becomes

$$
\bar{c}_{p}^{2}=A+s
$$

since parents will obviously leave no bequests and receive no transfers if their child is not alive in the second period.

In the second period, the child, now an adult, controls its own income. Child consumption, $c_{c}$, in the second period is given by

$$
c_{c}=h\left(1-l_{c}\right)+b-\tau
$$

We assume that the parents maximize an additive separable utility function given by

$$
W_{p}=U\left(c_{p}^{1}\right)+\left[p U\left(\tilde{c}_{p}^{2}\right)+(1-p) U\left(\bar{c}_{p}^{2}\right)\right]+p \delta W_{c}
$$

where $W_{c}$ corresponds to the child's utility function. Note that $W_{p}$ takes the form of an expected utility function since their child will be alive in the second period with probability $p$. The parameter $0<\delta<1$ measures the extent of the parental altruism.

Similarly, children maximize an additive separable utility function given by

$$
\begin{aligned}
W_{c} & =V\left(c_{c}\right)+\lambda\left[U\left(\tilde{c}_{p}^{2}\right)+\delta W_{c}\right] \\
& =\frac{V\left(c_{c}\right)+\lambda U\left(\tilde{c}_{p}^{2}\right)}{1-\delta \lambda}
\end{aligned}
$$

where $0<\lambda<1$ measures the extent of filial altruism. By construction, the child's utility function is conditional on child's survival, and so it does not take the form of an expected utility function.

Replacing (6) into (5), we obtain that parents actually maximize

$$
W_{p}=U\left(c_{p}^{1}\right)+p \frac{U\left(\tilde{c}_{p}^{2}\right)}{1-\delta \lambda}+(1-p) U\left(\bar{c}_{p}^{2}\right)+p \frac{\delta V\left(c_{c}\right)}{1-\delta \lambda}
$$

Throughout this paper, we assume that $U$ and $V$ are both twice continuously differentiable, strictly increasing, and strictly concave.

The sequence of events is as follows. In the first period, the parents choose the level of child labor and savings and, in the second period, they choose the level of bequests they will leave to their child. In both periods, they take into account the way in which these decision variables will affect $\tau$, the amount of filial transfers. 
The first-order conditions with respect to bequests, child labor and savings are respectively

$$
\begin{gathered}
U^{\prime}\left(\tilde{c}_{p}^{2}\right)=\delta V^{\prime}\left(c_{c}\right) \quad \text { and } \quad b>0 \\
U^{\prime}\left(\tilde{c}_{p}^{2}\right)>\delta V^{\prime}\left(c_{c}\right) \quad \text { and } \quad b=0 \\
U^{\prime}\left(c_{p}^{1}\right)+p \frac{U^{\prime}\left(\tilde{c}_{p}^{2}\right)}{1-\delta \lambda} \frac{d \tau}{d l_{c}}=p \frac{\delta V^{\prime}\left(c_{c}\right)}{1-\delta \lambda}\left[h^{\prime}\left(1-l_{c}\right)+\frac{d \tau}{d l_{c}}\right] \\
U^{\prime}\left(c_{p}^{1}\right)+p \frac{\delta V^{\prime}\left(c_{c}\right)}{1-\delta \lambda} \frac{d \tau}{d s}=p \frac{U^{\prime}\left(\tilde{c}_{p}^{2}\right)}{1-\delta \lambda}\left[1+\frac{d \tau}{d s}\right]+(1-p) U^{\prime}\left(\bar{c}_{p}^{2}\right)
\end{gathered}
$$

After having observed the decisions taken by the parents, the children choose the level of transfers they will perform in the behalf of their parents, $\tau$. The level of filial transfers is given by the following equation

$$
\begin{array}{llll}
V^{\prime}\left(c_{c}\right)=\lambda U^{\prime}\left(\tilde{c}_{p}^{2}\right) & \text { and } & & \tau>0 \\
V^{\prime}\left(c_{c}\right)>\lambda U^{\prime}\left(\tilde{c}_{p}^{2}\right) & \text { and } & \tau & =0
\end{array}
$$

Note that equations (8) and (12) cannot hold simultaneously, given the values of the parameters. Therefore in defining the level of child labor supply at equilibrium, there are three cases of interest: 1.Positive net bequests, that is, $b>0$ and $\tau=0$; 2. Negative net bequests, that is, $b=0$ and $\tau>0$; and 3 . Null net bequests, that is, $b=\tau=0$, in which the parents and the children choose to perform no transfers.

\subsection{Positive net bequests}

Here the parents expect to leave positive net bequests to their child. Combining (8), (10), and (11), we obtain that in this case the equilibrium level of child labor is characterized by

$$
h^{\prime}\left(1-l_{c}^{*}\right)=1+\frac{1-p}{p} \frac{U^{\prime}\left(\bar{c}_{p}^{2}\right)}{\frac{U^{\prime}\left(\tilde{c}_{p}^{2}\right)}{1-\delta \lambda}}
$$

\subsection{Negative net bequests}

In this second case, we consider that the parents are net receivers of filial transfers. Putting equations (10) and (11) together, and calculating $\frac{d \tau}{d l_{c}}$ and $\frac{d \tau}{d s}$ from (12), we obtain that the equilibrium level of child labor is characterized by 


$$
h^{\prime}\left(1-l_{c}^{*}\right)=1+\frac{\lambda U^{\prime \prime}\left(\tilde{c}_{p}^{2}\right)+V^{\prime \prime}\left(c_{c}\right)}{\delta \lambda^{2} U^{\prime \prime}\left(\tilde{c}_{p}^{2}\right)+V^{\prime \prime}\left(c_{c}\right)} \frac{1-p}{p} \frac{U^{\prime}\left(\bar{c}_{p}^{2}\right)}{\frac{U^{\prime}\left(\tilde{c}_{p}^{2}\right)}{1-\delta \lambda}}
$$

Note that when filial transfers are positive, there is an additional term in the expression that corresponds to the strategic effect of transfers on the parents' decision variables.

\section{$3.3 \quad$ Null net bequests}

Combining equations (10) and (11), we obtain the equation that corresponds to the equilibrium level of child labor when both the parents and the child do not make intergenerational transfers

$$
h^{\prime}\left(1-l_{c}^{*}\right)=\frac{U^{\prime}\left(\tilde{c}_{p}^{2}\right)}{\delta V^{\prime}\left(c_{c}\right)}+\frac{1-p}{p} \frac{U^{\prime}\left(\bar{c}_{p}^{2}\right)}{\frac{\delta V^{\prime}\left(c_{c}\right)}{1-\delta \lambda}}
$$

\section{Second Model: Perfect Insurance}

In order to evaluate the impact of children lifetime uncertainty on the parents' decision regarding child labor, we now consider the case in which parents can be insured against their child's premature death by means of an insurance contract.

The insurance contract is specified in the following way. In case of the child's premature death, the parents receive an indemnity equal to $I$ in the second period. The amount of such indemnity is chosen by the parents in order to maximize their expected utility. In order to contract this insurance, parents pay a premium, the value of which depends on the indemnity they will get in case their child dies prematurely. Assuming that the premium is actuarially fair (so that the premium is equal to the expected reimbursement), one obtains a premium equal to $(1-p) I$.

The introduction of perfect insurance markets modifies the parents' first period budget constraint, and the parents' second period budget constraint if their child is not alive. The parents' first period budget constraint becomes

$$
c_{p}^{1}=A+l_{c}-s-(1-p) I
$$

where $(1-p) I$ represents the premium parents have to pay to the insurance company. In the case their child does not survive the second period, the parents' budget constraint becomes

$$
\bar{c}_{p}^{2}=A+s+I
$$


since, according to the insurance contract, they will receive the amount $I$ as indemnity for their child's premature death.

Here parents maximize the joint expected utility function captured by equation (7) with respect to bequests, child labor, savings, and indemnity. The first-order conditions with respect to $b, l_{c}, s$, and $I$ are respectively equations (8), (9), (10), (11), and

$$
U^{\prime}\left(c_{p}^{1}\right)=U^{\prime}\left(\bar{c}_{p}^{2}\right)
$$

Thus, with perfect insurance, we have an additional first-order condition, equation (19), which corresponds to the optimal choice of insurance indemnity. This condition states that the parents choose $I$ in order to equalize their first period marginal utility and their second period marginal utility in the case of their child's premature death. This equation highlights the role of insurance contracts that allow parents to transfer risk by shifting wealth from the certain period to the uncertain one.

One should note that since all markets are perfect, if the intergenerational transfers are not binding,$l_{c}^{e}$, the equilibrium amount of child labor in this setting, is necessarily efficient.

We can now characterize the efficient level of child labor. In the case in which we have positive net bequests, we have to combine (8), (10), (11), and (19). If, instead, net bequests are negative, we have to combine equations (10), (11), (19), and compute $\frac{d \tau}{d l_{c}}$ and $\frac{d \tau}{d s}$ from (12). In both cases, we obtain

$$
h^{\prime}\left(1-l_{c}^{e}\right)=\frac{1}{p}
$$

which is the condition that characterizes the efficient level of child labor. As one could expect, the efficient level of child labor is decreasing in the probability of survival.

\section{Main Results}

In this Section, we establish the main findings related to the interaction between child's lifetime uncertainty and the supply of child labor. We show that the uncertainty concerning the child's lifetime may lead parents to choose inefficient levels of child labor in the absence of insurance mechanisms.

Proposition 1 establishes the result concerning the interaction between mortality rates and the supply of child labor. 
Proposition 1. With or without perfect insurance markets, an increase in child mortality increases the amount of child labor supplied.

A proof of this result is presented in the Appendix for the case of positive net bequests. The interpretation of this result is straightforward. An increase in mortality rates lowers the expected return to education, and thereby decreases education investment, or similarly, increases child labor. Therefore countries in which the surviving probability is lower should exhibit greater levels of child labor. In such settings it is privately efficient from the parents' point of view to put the children at work instead of school.

Nevertheless we next show that the impact of mortality on child labor goes beyond this effect through the rates of return from education. Indeed uncertainty concerning the child's lifetime may lead parents to choose inefficient levels of child labor in the absence of insurance mechanisms. The rest of this section is devoted to discuss this issue.

Generally the effect of lifetime uncertainty on the parents' decisions concerning the level of child labor depends on the levels of the altruism parameters. For the sake of clarity, we solve for particular cases of the two-sided altruism model. We start by analyzing the case in which the parents are not altruist towards their child and next the opposite case characterized by the absence of filial altruism. We then analyze the setting characterized by the absence of intergenerational transfers.

\subsection{Case 1: Absence of parental altruism}

We now turn to the situation in which $\delta=0$, that is, no parental altruism, which implies $b=0$. We concentrate in the case in which the children do make positive transfers to their parents. We note that such a setting corresponds to the "old-age security model".

Proposition 2. In the absence of parental altruism, if the parents expect to receive positive transfers from their child and there is uncertainty concerning their child's lifetime, the level of child labor they will chose is inefficiently high in the absence of insurance markets.

Proof. We can easily find this result by replacing the values of the parameters, $\delta=0$ and $\lambda>0$ into (15), and comparing the resulting equation to (20), taking into account (2) and (3), since in this case we have $\bar{c}_{p}^{2}<\tilde{c}_{p}^{2}$.

This result is quite intuitive. Its explanation lies in the fact that educational investment yields positive gains to the child in the second period through higher wages, but also to the parents, via the transfers, while child labor guarantees an 
income to parents in the first period. If risk-averse parents know that their child has a positive probability of not being alive in the second period and, consequently, not materializing gains from education investment, they will prefer to put their child to work in the first period, and anticipate part of the transfers. So, if as in the old-age security model, parents are net receivers, the possible event of their child's death reduces their expected income in the second period, and, as a result, parents will prefer to increase their income in the first period and save more, so as to transfer a "sure" income to the second period.

\subsection{Case 2: Absence of filial altruism}

The first case we consider corresponds to the absence of filial altruism, that is, $\lambda=0$. Note that in this case the child does not make any transfer to its parents, that is, $\tau=0$. In principle, parents may leave positive or null bequests to their children. Here we concentrate in the case in which the parental altruism parameter is large enough so that parents leave positive bequests to their child.

Proposition 3. In the absence of filial altruism, if the parents expect to leave positive bequests to their child and there is uncertainty concerning their child's lifetime, the level of child labor they will chose is inefficiently low in the absence of insurance markets.

Proof. We obtain the result simply by replacing the values of the parameters, $\lambda=0$ and $\delta>0$, into (14) and comparing it to (20), taking into account that since $b>0$ and $\tau=0, \bar{c}_{p}^{2}>\tilde{c}_{p}^{2}$.

This result is counterintuitive. Indeed, at first sight, one may be lead to think that, in the absence of insurance, parents would rather choose the "sure" income (i.e., child labor) at the expense of the uncertain one (i.e., child education). The proposition above shows that this intuition is not true in case of positive net bequests. The reason is that parents have two ways to make transfers to their child: making their child work, saving and then leaving them a bequest, or providing them with education that increases their child's human capital and therefore raises their wage in the future. If the child dies in the second period, in both cases, it will not be able to enjoy these transfers. However the transfer through savings and bequests presents an additional inconvenient if the child dies: the cost parents have to incur of being left with too much resources in the second period, since they will not be able to leave a bequest to their child. For this reason, parents prefer to invest more in education if they know that they will make a positive net transfer, and that their child has a positive probability of dying. 


\subsection{Case 3: Null bequests and transfers}

Proposition 4. In the absence of intergenerational transfers, if there is uncertainty concerning their child's lifetime, the level of child labor they will chose is inefficiently low in the absence of insurance markets.

Proof. We can easily find this result by replacing the values of the parameters, $\delta=0$ and $\lambda>0$ into (16), and comparing the resulting equation to (20), since in this case we have $\bar{c}_{p}^{2}=\tilde{c}_{p}^{2}$.

\section{Efficiency-restoring Policy Interventions}

In Section 5 we have shown that, in the absence of insurance markets, parents may choose an inefficiently high or low level of child labor depending on the parental and the filial altruism levels. In this Section we evaluate the effectiveness of some alternative policy interventions to restore efficiency in such a setting.

We argue that Case 1 is the one in which we should concentrate our attention. Indeed the role of filial transfers as an old-age security device is well-documented in developing countries (see for example Cain (1982) and Nugent (1985)).

Obviously a tax schedule that reproduces the perfect insurance scheme can restore efficiency ${ }^{8}$. However we assume that perfect insurance contracts or other equivalent tax schedules are not available.

We rather concentrate on alternative policy options. The first policy we discuss is public pension. Since we have concluded that the inefficiently high level of child labor is related to the old-age security motive, public pensions seem to be, at first sight, an appropriate policy to avoid this inefficiency. However, since in our setting we have assumed the existence of perfect capital markets, the effect of public pensions can be shown to be innocuous.

We now turn our attention to cash transfers conditional on child's education. Since conditional cash transfers constitute an incentive for education investment to the detriment of child labor, they could potentially avoid the inefficiently high level of child labor.

\subsection{Cash transfers conditional on child's schooling}

Here we turn our attention to cash transfers conditional on child's schooling such as Bolsa Escola in Brazil and PROGRESA in Mexico. The conditional cash transfer

\footnotetext{
${ }^{8}$ In Section 4, we have discussed the fact that with perfect insurance markets, the level of child labor is actually efficient.
} 
provides an additional incentive for sending children to school and alleviates the resource constraint of households in the absence of child labor earnings.

We consider that in the first period parents receive a cash transfer proportional to the amount of education they provide for their children, $1-l_{c}$. We suppose that this transfer is financed by a tax levied on surviving children. The amount of the tax that a surviving child will pay is independent of its own education level, but rather depends on the total level of education received by all children in this economy (and we assume that the economy is populated by a large number of individuals). Thus the tax is an exogenous variable in parents' decision ${ }^{9}$.

We next present our main result concerning this policy scheme.

Proposition 5. Cash transfers conditional on the child's education being financed by a tax levied on the surviving children or on the parents can restore efficiency in the parental decision regarding child labor.

Proof. Here the parents' first period budget constraint is

$$
c_{p}^{1}=A+l_{c}-s+\kappa\left(1-l_{c}\right)
$$

where $\kappa$ corresponds to the cash transfer per unit of education provided, and $\kappa\left(1-l_{c}\right)$ is the total cash transfer received. The parents' second period budget constraints are equations (2) and (3).

Assuming that this policy does not generate a public deficit, the child's second period budget constraint equals

$$
c_{c}=h\left(1-l_{c}\right)+b-\tau-\frac{\eta}{p}
$$

where $\eta$ equals the average cash transfer received by all children (including children who did not survive for the second period), and $\frac{\eta}{p}$ the amount of the tax that each surviving children actually pays.

As before, we suppose that the child's utility function is represented by equation (6). The optimal choice of $\tau$ conditional on $l_{c}, s$, and $b$ satisfies (12). The first-order condition that characterizes the parental decision concerning savings corresponds to equation (11). The first-order condition with respect to $l_{c}$ becomes

$$
U^{\prime}\left(c_{p}^{1}\right)(1-\kappa)+p \frac{U^{\prime}\left(\tilde{c}_{p}^{2}\right)}{1-\delta \lambda} \frac{d \tau}{d l_{c}}=p \frac{\delta V^{\prime}\left(c_{c}\right)}{1-\delta \lambda}\left[h^{\prime}\left(1-l_{c}\right)+\frac{d \tau}{d l_{c}}\right]
$$

\footnotetext{
${ }^{9}$ Therefore our results do not change if we consider alternative financing mechanisms, such as a tax levied on the parents' first or second period income or a budget deficit. These schemes have no impact on the parental decision but only on the amount of final wealth of the agents.
} 
Combining equations (23) and (11), computing $\frac{d \tau}{d l_{c}}$ and $\frac{d \tau}{d s}$ from (12), and setting $\delta=0$, we obtain

$$
h^{\prime}\left(1-l_{c}\right)=(1-\kappa)\left[1+\frac{\lambda U^{\prime \prime}\left(\tilde{c}_{p}^{2}\right)+V^{\prime \prime}\left(c_{c}\right)}{V^{\prime \prime}\left(c_{c}\right)} \frac{1-p}{p} \frac{U^{\prime}\left(\bar{c}_{p}^{2}\right)}{U^{\prime}\left(\tilde{c}_{p}^{2}\right)}\right]
$$

As one could expect, if $\kappa=0$, we retrieve the equilibrium level of child labor corresponding to Case 1 . If $\kappa=1$, the cash transfer fully compensates parents for the highest revenue they could obtain from child labor and therefore they choose a level of child labor equal to zero. Since we are in the case in which parental altruism is zero, we know that the efficient level of child labor is in between 0 and the equilibrium level. Thus if child labor supply is a continuous function of the cash transfer, we know that there is a level of cash transfer leading to the efficient level of child labor. Finally we just have to note that the continuity of the labor supply is actually implied by the assumptions we have made regarding the utility function, namely that $U$ and $V$ are both twice continuously differentiable, and strictly concave.

This result shows that an appropriate system of conditional cash transfers can actually reduce the inefficiently high level of child labor to the efficient one when parental altruism is low, no matter how we choose to finance such transfers. Obviously an appropriate conditional cash transfers system can eradicate child labor, if it fully compensates parents for maximum child labor earnings.

Finally we emphasize that the introduction of conditional cash transfers can restore efficiency in parents' decisions concerning child labor, but certainly do not guarantee global efficiency. Indeed, in this setting, bequests, savings and transfers will be typically inefficient.

\section{Conclusion}

In this paper we have modified Baland and Robinson's (2000) model to account for the child's lifetime uncertainty.

We have shown that the consequences of lifetime uncertainty on child labor may be severe. Indeed, it may explain why parents may choose an inefficient level of child labor even if capital markets are perfect. Interestingly we have shown that the equilibrium level is not necessarily higher than the efficient level, as one would expect at first sight. In fact the equilibrium level is higher than the efficient level if non-altruistic parents expect to receive positive net transfers from their child, and lower if altruistic parents expect to leave positive net bequests to non-altruistic children. 
We have next turned our attention to alternative policies that could potentially restore efficiency in parents' decisions concerning child labor. We have shown that a public pensions system is not an appropriate mechanism to remedy this inefficiency. In contrast, appropriate cash transfers conditional on child's schooling may restore efficiency.

\section{References}

Baland, J. M. and Robinson, J. A. (2000). Is child labor inefficient. Journal of Political Economy, 108(4):663-679.

Basu, K. and Van, P. H. (1998). The economics of child labor. The American Economic Review, 88(3):412-427.

Becker, G. S. (1964). Human Capital: A Theoretical and Empirical Analysis, with Special Reference to Education. Columbia university press. National Bureau of Economic Research, New York, 1nd edition.

Cain, M. (1982). Perspectives on family and fertility in developing countries. Population Studies, 36(2):159-175.

Couralet, P.-E. (2002). Une analyse économique du travail des enfants. Phd thesis, Ecole des hautes études en sciences sociales.

Edmonds, E. V. (2004). Does illiquidity alter child labor and schooling decisions? evidence from household responses to anticipated cash transfers in south africa. NBER Working Paper, w10265.

Eswaran, M. (2000). Institutions, Incentives and Economic Reforms in India, chapter 9, pages 267-296. Sage India.

Levhari, D. and Weiss, Y. (1974). The effect of risk on the investment in human capital. The American Economic Review, 64(6):950-963.

Nugent, J. B. (1985). The old-age security motive for fertility. Population and Development Review, 11(1):75-97.

Psacharopoulos, G. (1997). Child labor versus educational attainement. some evidence from latin america. Journal of Population Economics, 10:377-386.

Razin, A. (1976). Lifetime uncertainty, human capital and physical capital. Economic Inquiry, 14:439-448. 
Strulik, H. (2004). Child mortality, child labour and economic development. The Economic Journal, 114:547-568.

\section{A Proof of Proposition 1}

\section{A.1 Positive net bequests}

We concentrate in the case in which bequests are positive and so filial transfers are nil. The first-order conditions are (8), (10), and (11) with $\frac{d \tau}{d l_{c}}=0$ and $\frac{d \tau}{d s}=0$. These equations then define three implicit equations, namely

$$
\begin{aligned}
& F_{1}\left(l_{c}, s, b ; p, \lambda, \delta\right)=\delta V^{\prime}\left(h\left(1-l_{c}\right)-U^{\prime}(A-b+s)=0\right. \\
& F_{2}\left(l_{c}, s, b ; p, \lambda, \delta\right)=U^{\prime}\left(A+l_{c}-s\right)-p \frac{\delta V^{\prime}\left(h\left(1-l_{c}\right)+b\right)}{1-\delta \lambda} h^{\prime}\left(1-l_{c}\right)=0 \\
& F_{3}\left(l_{c}, s, b ; p, \lambda, \delta\right)=-U^{\prime}\left(A+l_{c}-s\right)+p \frac{U^{\prime}(A-b+s)}{1-\delta \lambda}+(1-p) U^{\prime}(A+s)=0
\end{aligned}
$$

From the implicit function theorem, we know that

$$
\left(\begin{array}{c}
\frac{d b}{d p} \\
\frac{d l_{c}}{d p} \\
\frac{d s}{d p}
\end{array}\right)=-\left(\begin{array}{lll}
\frac{\partial F_{1}}{\partial b} & \frac{\partial F_{1}}{\partial l_{c}} & \frac{\partial F_{1}}{\partial s} \\
\frac{\partial F_{2}}{\partial b} & \frac{\partial F_{2}}{\partial l_{c}} & \frac{\partial F_{2}}{\partial s} \\
\frac{\partial F_{3}}{\partial b} & \frac{\partial F_{3}}{\partial l_{c}} & \frac{\partial F_{3}}{\partial s}
\end{array}\right)^{-1}\left(\begin{array}{c}
\frac{\partial F_{1}}{\partial p} \\
\frac{\partial F_{2}}{\partial p} \\
\frac{\partial F_{3}}{\partial p}
\end{array}\right)
$$

Applying it to the implicit equations (25), (26), and (27), we obtain

$$
\begin{aligned}
\left(\begin{array}{c}
\frac{d b}{d p} \\
\frac{d l c}{d p} \\
\frac{d s}{d p}
\end{array}\right)= & \\
& -\left(\begin{array}{ccc}
\delta V^{\prime \prime}\left(c_{c}\right)+U^{\prime \prime}\left(\tilde{c}_{p}^{2}\right) & -\delta V^{\prime \prime}\left(c_{c}\right) h^{\prime} & -U^{\prime \prime}\left(\tilde{c}_{p}^{2}\right) \\
-p \frac{\delta V^{\prime \prime}\left(c_{c}\right)}{1-\delta \lambda} h^{\prime} & U^{\prime \prime}\left(c_{p}^{1}\right)+p \frac{\delta V^{\prime \prime}\left(c_{c}\right)}{1-\delta \lambda}\left[h^{\prime}\right]^{2}+p \frac{\delta V^{\prime}\left(c_{c}\right)}{1-\delta \lambda} h^{\prime \prime} & -U^{\prime \prime}\left(c_{p}^{1}\right) \\
-p \frac{U^{\prime \prime}\left(\tilde{c}_{p}^{2}\right)}{1-\delta \lambda} & -U^{\prime \prime}\left(c_{p}^{1}\right) & U^{\prime \prime}\left(c_{p}^{1}\right)+p \frac{U^{\prime \prime}\left(\tilde{c}_{p}^{2}\right)}{1-\delta \lambda}+(1-p) U^{\prime \prime}\left(\bar{c}_{p}^{2}\right)
\end{array}\right)^{-1} \\
& \cdot\left(\begin{array}{c}
0 \\
-\delta V^{\prime}\left(c_{c}\right) h^{\prime} \\
\frac{U^{\prime}\left(\tilde{c}_{p}^{2}\right)}{1-\delta \lambda}-U^{\prime}\left(\bar{c}_{p}^{2}\right)
\end{array}\right)
\end{aligned}
$$

The determinant of this matrix is negative due to the concavity of this problem.

Thus we can express $\frac{d l_{c}}{d p}$ as 


$$
\begin{aligned}
\frac{d l_{c}}{d p} & =\left\{\left[\delta V^{\prime \prime}\left(c_{c}\right)+U^{\prime \prime}\left(\tilde{c}_{p}^{2}\right)\right]\left[U^{\prime \prime}\left(c_{p}^{1}\right)+p \frac{U^{\prime \prime}\left(\tilde{c}_{p}^{2}\right)}{1-\delta \lambda}+(1-p) U^{\prime \prime}\left(\bar{c}_{p}^{2}\right)\right]-p \frac{\left[U^{\prime \prime}\left(\tilde{c}_{p}^{2}\right)\right]^{2}}{1-\delta \lambda}\right\}\left[-\frac{\delta V^{\prime}\left(c_{c}\right)}{1-\delta \lambda} h^{\prime}\left(1-l_{c}\right)\right] \\
& -\left\{\left[\delta V^{\prime \prime}\left(c_{c}\right)+U^{\prime \prime}\left(\tilde{c}_{p}^{2}\right)\right]\left[-U^{\prime \prime}\left(c_{p}^{1}\right)\right]-U^{\prime \prime}\left(\tilde{c}_{p}^{2}\right)\left[p \frac{\delta V^{\prime \prime}\left(c_{c}\right)}{1-\delta \lambda} h^{\prime}\left(1-l_{c}\right)\right]\right\}\left[\frac{U^{\prime}\left(\tilde{c}_{p}^{2}\right)}{1-\delta \lambda}-U^{\prime}\left(\bar{c}_{p}^{2}\right)\right] \\
& =\left\{\left[\delta V^{\prime \prime}\left(c_{c}\right)+U^{\prime \prime}\left(\tilde{c}_{p}^{2}\right)\right]\left[U^{\prime \prime}\left(c_{p}^{1}\right)+(1-p) U^{\prime \prime}\left(\bar{c}_{p}^{2}\right)\right]+p \frac{U^{\prime \prime}\left(\tilde{c}_{p}^{2}\right)}{1-\delta \lambda} \delta V^{\prime \prime}\left(c_{c}\right)\right\}\left[-\frac{\delta V^{\prime}\left(c_{c}\right)}{1-\delta \lambda} h^{\prime}\left(1-l_{c}\right)\right] \\
& +\left\{\left[\delta V^{\prime \prime}\left(c_{c}\right)+U^{\prime \prime}\left(\tilde{c}_{p}^{2}\right)\right] U^{\prime \prime}\left(c_{p}^{1}\right)+U^{\prime \prime}\left(\tilde{c}_{p}^{2}\right)\left[p \frac{\delta V^{\prime \prime}\left(c_{c}\right)}{1-\delta \lambda} h^{\prime}\left(1-l_{c}\right)\right]\right\}\left[\frac{U^{\prime}\left(\tilde{c}_{p}^{2}\right)}{1-\delta \lambda}-U^{\prime}\left(\bar{c}_{p}^{2}\right)\right]
\end{aligned}
$$

Combining (26) and (27) we obtain

$$
\frac{\delta V^{\prime}\left(c_{c}\right)}{1-\delta \lambda} h^{\prime}\left(1-l_{c}\right)=\frac{U^{\prime}\left(\tilde{c}_{p}^{2}\right)}{1-\delta \lambda}+\frac{1-p}{p} U^{\prime}\left(\bar{c}_{p}^{2}\right)
$$

Replacing (29) into (30), combining it with (14) and simplifying the resulting equation, we obtain

$$
\begin{aligned}
\frac{d l_{c}}{d p} & =-p U^{\prime}\left(\bar{c}_{p}^{2}\right) U^{\prime \prime}\left(\tilde{c}_{p}^{2}\right) \frac{\delta V^{\prime \prime}\left(c_{c}\right)}{1-\delta \lambda}-(1-p) \frac{\left[U^{\prime}\left(\bar{c}_{p}^{2}\right)\right]^{2}}{U^{\prime}\left(\tilde{c}_{p}^{2}\right)} U^{\prime \prime}\left(\tilde{c}_{p}^{2}\right) \delta V^{\prime \prime}\left(c_{c}\right)-\frac{1}{p} U^{\prime}\left(\bar{c}_{p}^{2}\right)\left[U^{\prime \prime}\left(c_{p}^{1}\right) \delta V^{\prime \prime}\left(c_{c}\right)+U^{\prime \prime}\left(c_{p}^{1}\right) U^{\prime \prime}\left(\tilde{c}_{p}^{2}\right)\right] \\
& -\left[\frac{U^{\prime}\left(\tilde{c}_{p}^{2}\right)}{1-\delta \lambda}-\frac{1-p}{p} U^{\prime}\left(\bar{c}_{p}^{2}\right)\right]\left[(1-p) U^{\prime \prime}\left(\bar{c}_{p}^{2}\right) \delta V^{\prime \prime}\left(c_{c}\right)+(1-p) U^{\prime \prime}\left(\bar{c}_{p}^{2}\right) U^{\prime \prime}\left(\tilde{c}_{p}^{2}\right)\right]<0
\end{aligned}
$$




\section{A.2 Negative net bequests}

We concentrate in the case in which filial transfers are positive and so bequests are equal to zero. The first-order conditions are (10), (11), and (12). These equations then define three implicit equations, namely

$$
\begin{aligned}
& G_{1}\left(l_{c}, s, \tau ; p, \lambda, \delta\right)=-V^{\prime}\left(h\left(1-l_{c}\right)-\tau\right)+\lambda U^{\prime}(A+s+\tau)=0 \\
& G_{2}\left(l_{c}, s, \tau ; p, \lambda, \delta\right)=U^{\prime}\left(A+l_{c}-s\right)+p \frac{U^{\prime}(A+s+\tau)}{1-\delta \lambda} \frac{d \tau}{d l_{c}}-p \frac{\delta V^{\prime}\left(h\left(1-l_{c}\right)-\tau\right)}{1-\delta \lambda}\left[h^{\prime}\left(1-l_{c}\right)+\frac{d \tau}{d l_{c}}\right]=0 \\
& G_{3}\left(l_{c}, s, \tau ; p, \lambda, \delta\right)=-U^{\prime}\left(A+l_{c}-s\right)-p \frac{\delta V^{\prime}\left(h\left(1-l_{c}\right)-\tau\right)}{1-\delta \lambda} \frac{d \tau}{d s}+p \frac{U^{\prime}(A+s+\tau)}{1-\delta \lambda}\left[1+\frac{d \tau}{d s}\right]+(1-p) U^{\prime}(A+s)=0
\end{aligned}
$$

From the implicit function theorem, we know that

$$
\left(\begin{array}{c}
\frac{d \tau}{d p} \\
\frac{d l_{c}}{d p} \\
\frac{d s}{d p}
\end{array}\right)=-\left(\begin{array}{lll}
\frac{\partial G_{1}}{\partial \tau} & \frac{\partial G_{1}}{\partial l_{c}} & \frac{\partial G_{1}}{\partial s} \\
\frac{\partial G_{2}}{\partial \tau} & \frac{\partial G_{2}}{\partial l_{c}} & \frac{\partial G_{2}}{\partial s} \\
\frac{\partial G_{3}}{\partial \tau} & \frac{\partial G_{3}}{\partial l_{c}} & \frac{\partial G_{3}}{\partial s}
\end{array}\right)^{-1}\left(\begin{array}{c}
\frac{\partial G_{1}}{\partial p} \\
\frac{\partial G_{2}}{\partial p} \\
\frac{\partial G_{3}}{\partial p}
\end{array}\right)
$$

Applying it to the implicit equations (32), (33), and (34), we obtain

$$
\begin{aligned}
& =-\left(\begin{array}{ccc}
V^{\prime \prime}\left(c_{c}\right)+\lambda U^{\prime \prime}\left(\tilde{c}_{p}^{2}\right) & V^{\prime \prime}\left(c_{c}\right) h^{\prime} & \lambda U^{\prime \prime}\left(\tilde{c}_{p}^{2}\right) \\
p \frac{U^{\prime \prime}\left(\tilde{c}_{p}^{2}\right)}{d l_{c}}+p \frac{\delta V^{\prime \prime}\left(c_{c}\right)}{1-\delta \lambda}\left[h^{\prime}+\frac{d \tau}{d l_{c}}\right] & U^{\prime \prime}\left(c_{p}^{1}\right)+p \frac{\delta V^{\prime \prime}\left(c_{c}\right)}{1-\delta \lambda} h^{\prime}\left[h^{\prime}+\frac{d \tau}{d l_{c}}\right] & -U^{\prime \prime}\left(c_{p}^{1}\right)+p \frac{U^{\prime \prime}\left(\tilde{c}_{p}^{2}\right)}{1-\delta \lambda} \frac{d \tau}{d l_{c}} \\
p \frac{\delta V^{\prime \prime}\left(c_{c}\right)}{1-\delta \lambda} \frac{d \tau}{d s}+p \frac{U^{\prime \prime}\left(\tilde{c}_{p}^{2}\right)}{1-\delta \lambda}\left[1+\frac{d \tau}{d s}\right] & -U^{\prime \prime}\left(c_{p}^{1}\right)+p \frac{\delta V^{\prime \prime}\left(c_{c}\right)}{1-\delta \lambda} \frac{d \tau}{d s} h^{\prime} & U^{\prime \prime}\left(c_{p}^{1}\right)+p \frac{U^{\prime \prime}\left(\tilde{c}_{p}^{2}\right)}{1-\delta \lambda}\left[1+\frac{d \tau}{d s}\right]+(1-p) U^{\prime \prime}\left(\bar{c}_{p}^{2}\right)
\end{array}\right)^{-1} \\
& \left(\begin{array}{c}
0 \\
\frac{U^{\prime}\left(\tilde{c}_{p}^{2}\right)}{1-\delta \lambda} \frac{d \tau}{d l_{c}}-\frac{\delta V^{\prime}\left(c_{c}\right)}{1-\delta \lambda}\left[h^{\prime}+\frac{d \tau}{d l_{c}}\right] \\
-\frac{\delta V^{\prime}\left(c_{c}\right)}{1-\delta \lambda} \frac{d \tau}{d s}+\frac{U^{\prime}\left(\tilde{c}_{p}^{2}\right)}{1-\delta \lambda}\left[1+\frac{d \tau}{d s}\right]-U^{\prime}\left(\bar{c}_{p}^{2}\right)
\end{array}\right)
\end{aligned}
$$

The determinant of this matrix is negative due to the concavity of this problem. Thus we can express $\frac{d l_{c}}{d p}$ as 